\title{
Lipid complex effect on fatty acid profile and chemical composition of cow milk and cheese
}

\author{
R. Bodkowski, ${ }^{\star 1}$ K. Czyż, ${ }^{\star}$ R. Kupczyński,† B. Patkowska-Sokoła, ${ }^{*}$ P. Nowakowski, ${ }^{*}$ and A. Wiliczkiewiczł \\ *Institute of Animal Breeding. \\ †Department of Environment Hygiene and Animal Welfare, and \\ $\ddagger$ Department of Animal Nutrition and Feed Management, Faculty of Biology and Animal Science, \\ Wroclaw University of Environmental and Life Sciences, Chelmonskiego 38c, 51-630 Wroclaw, Poland
}

\begin{abstract}
The effect of administration of lipid complex (LC) on cow milk and cheese characteristics was studied. Lipid complex was elaborated based on grapeseed oil with synthesized conjugated linoleic acid (CLA) and Atlantic mackerel oil enriched in n-3 fatty acids. The 4 -wk experiment was conducted on 30 Polish Holstein Friesian cows. The experimental group cow diet was supplemented with $400 \mathrm{~g} / \mathrm{d}$ of LC (containing 38\% CLA, and eicosapentaenoic acid + docosahexaenoic acid in a relative amount of $36.5 \%$ ) on a humic-mineral carrier. The chemical composition and fatty acid profile of milk and rennet cheese from raw fresh milk were analyzed. Lipid complex supplementation of the total mixed ration had no effect on milk yield and milk composition, except fat content, which decreased from 4.6 to $4.1 \%$, a $10.9 \%$ decrease. Milk from cows treated with LC had greater relative amounts of unsaturated fatty acids, particularly polyunsaturated fatty acids, and lesser relative amounts of saturated fatty acids. Lipid complex addition changed milk fat fatty acid profile: C18:2 cis-9,trans-11 and trans-10,cis-12 isomer (CLA) contents increased by 278 and $233 \%$, respectively, as did eicosapentaenoic acid (C20:5) and docosahexaenoic acid (C22:6) contents. Milk fat fatty acid profile changes were correlated with the modifications in rennet cheese fatty acid profile. Lipid complex supplementation of dairy cows produced considerable changes in the biological value of milk and cheese fat.
\end{abstract}

Key words: dairy cow, lipid complex, milk and cheese, fatty acid

\section{INTRODUCTION}

In recent years, functional foods and bioactive food components have drawn a lot of attention and interest

Received January 8, 2015.

Accepted September 6, 2015.

${ }^{1}$ Corresponding author: robert.bodkowski@up.wroc.pl of food scientists, nutritionists, and general consumers. Milk and milk products are valuable foods constituting an important part of the human diet. Fatty acid composition largely determines the quality of fat, and their properties depend on carbon chain length, number of unsaturated bonds, and cis or trans geometric configuration (Markiewicz-Kęszycka et al., 2013).

Essential fatty acids of the n- 3 and n- 6 families are PUFA that are not synthesized by the human organism and must be supplied in the diet. The fatty acids essential for normal human development are linoleic C18:2 (n-6), $\alpha$-linolenic C18:3 (n-3), eicosapentaenoic C20:5 (n-3; EPA), docosahexaenoic C22:6 (n-3; DHA), $\gamma$-linolenic C18:3 (n-6), and arachidonic C20:4 (n-6) acids (Simopoulos, 2008). Health-promoting properties are also attributed to CLA (Dilzer and Park, 2012).

Products derived from ruminants, especially milk fat, are an important source of CLA in the human diet (Khanal and Olson, 2004). High biological activity is exhibited by the cis-9,trans-11 C18:2, which constitutes about 75 to $95 \%$ of all milk fat CLA isomers (Bauman et al., 2008). Even up to $80 \%$ of the CLA cis-9,trans-11 isomer may originate from endogenous synthesis in the mammary gland (Kay et al., 2004). Milk fat is in turn characterized by a small amount of EPA and DHA (Donovan et al., 2000; Osborne et al., 2008).

Generally, the fatty acid profile of milk fat shows considerable variation, with diet being the primary determinant (Moate et al., 2008). Milk from pasture-fed cows had statistically significantly greater amounts of UFA, including CLA and C81:3, and smaller amounts of SFA, compared with milk from TMR-fed cows (Rego et al., 2004; Schroeder et al., 2005). The concentration of CLA and n-3 can be increased in cow milk by the application of plant oils (Puppel et al., 2013), raw (Donovan et al., 2000; Osborne et al., 2008) and protected fish oil (Castañeda-Gutiérrez et al., 2007; Kupczyński et al., 2012), fish and plant oils used concomitantly (AbuGhazaleh and Holmes, 2007), fish oil with algae (AbuGhazaleh et al., 2009), and encapsulated fish oil or microalgae (Vahmani et al., 2013). The concentration 


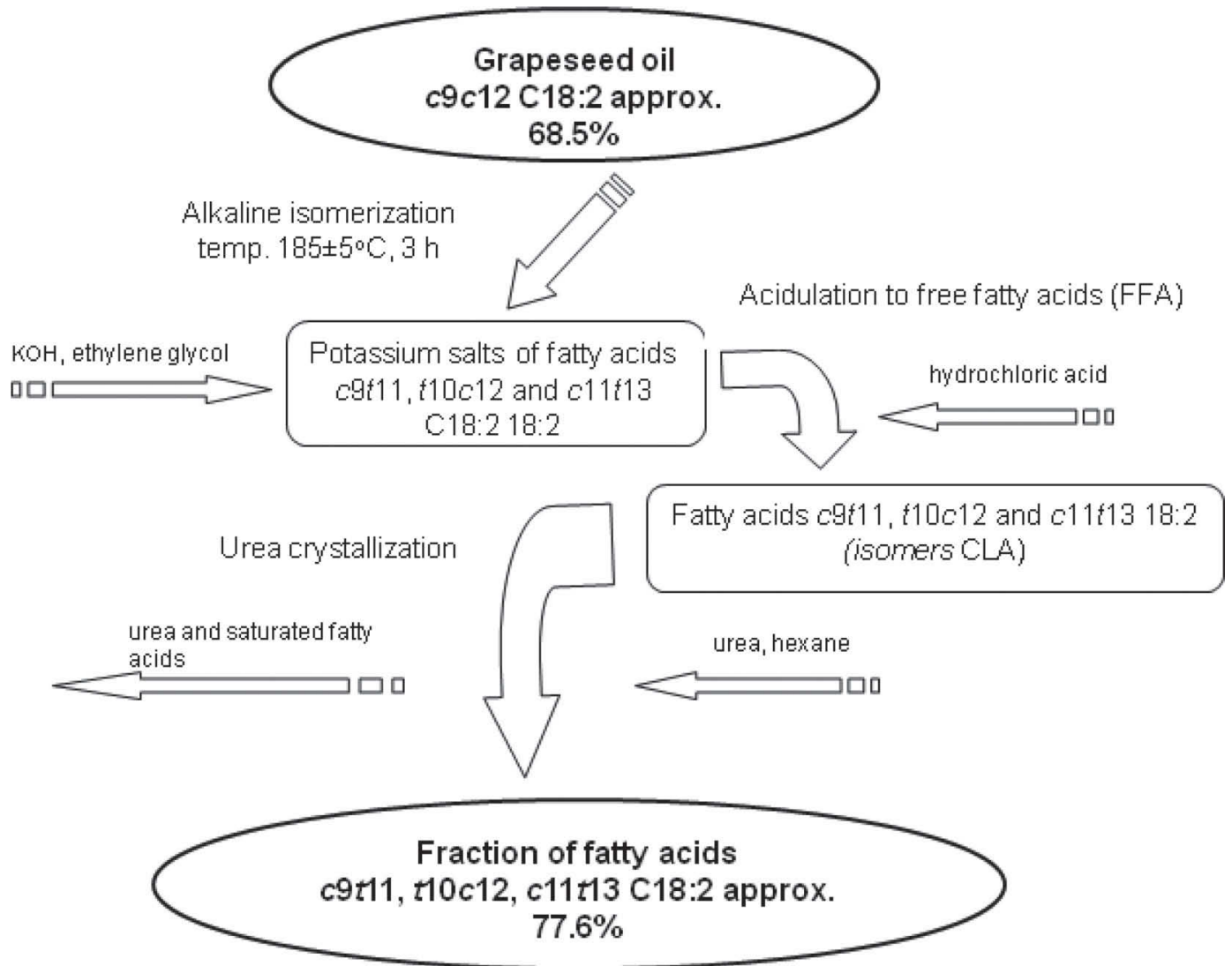

Figure 1. Scheme of grapeseed oil enrichment in c-9,t-11 and t-10,c-12 C18:2 acids. $\mathrm{c}=$ cis; $\mathrm{t}=$ trans, approx. $=$ approximately.

of CLA in milk can be increased through supplementing the ration of animals with CLA in nonprotected (Bodkowski et al., 2008) or protected form (Medeiros et al., 2010).

The aim of the present feeding trial was to investigate the influence of lipid complex (LC) based on grapeseed oil with synthesized CLA and Atlantic mackerel oil enriched in n-3 PUFA, on the content of fatty acids and chemical composition of milk and cheese.

\section{MATERIALS AND METHODS}

\section{Production of Oil Preparations and Elaboration of $L C$ and Feed Additive}

The synthesis of CLA isomers from plant oil was conducted according to the methodology elaborated by Walisiewicz-Niedbalska et al. (2009) using the process of alkaline isomerization and urea crystallization (Figure 1). The raw material was grapeseed oil of foodgrade quality (Monini Polska Ltd., Poznań, Poland). The synthesis also involved ethylene glycol (pure for analysis grade, p.a.), potassium hydroxide (p.a.), con- centrated hydrochloric acid (p.a.), anhydrous sodium sulfate (p.a.), urea (p.a.), and hexane as a solvent (all reagents: Avantor Performance Materials Poland Inc., Gliwice, Poland).

Fatty acid methyl esters were determined using the procedures described previously by Christopherson and Glass (1969). The chromatographic analysis was performed on a Hewlett Packard 5890 gas chromatograph with a flame-ionization detector (FID), Supelco SP2560 capillary GC column $[100 \mathrm{~m}$ length $\times 0.25 \mathrm{~mm}$ i.d., film thickness $\left(\mathbf{d}_{\mathbf{f}}\right)=0.20 \mu \mathrm{m}$; Supelco, Bellefonte, PA]. The following oven program was used: $140^{\circ} \mathrm{C}$ for $1 \mathrm{~min}$, increase by $1^{\circ} \mathrm{C} / \mathrm{min}$ to $180^{\circ} \mathrm{C}$, isotherm for $26 \mathrm{~min}$, increase by $5^{\circ} \mathrm{C} / \mathrm{min}$ to $245^{\circ} \mathrm{C}$, isotherm $25 \mathrm{~min}$; detector temperature $255^{\circ} \mathrm{C}$; dispenser temperature: split $245^{\circ} \mathrm{C}$; helium as a carrier gas $(0.98 \mathrm{~mL} / \mathrm{min})$. Identification of common fatty acids was accomplished by comparison of sample peak retention times with those of FAME standard mixtures (47885-U Supelco; Sigma-Aldrich Chemie GmbH, Schelldorf, Germany), trans-11-octadecenoic methyl ester (46905-U Supelco; Sigma-Aldrich Chemie GmbH), cis-9,trans-11-octadecadienoate methyl (20-1823-7; Larodan Fine Chemicals AB, Malmö, 
Table 1. Fatty acid composition in grapeseed oil, Atlantic mackerel oil, and lipid complex (LC)

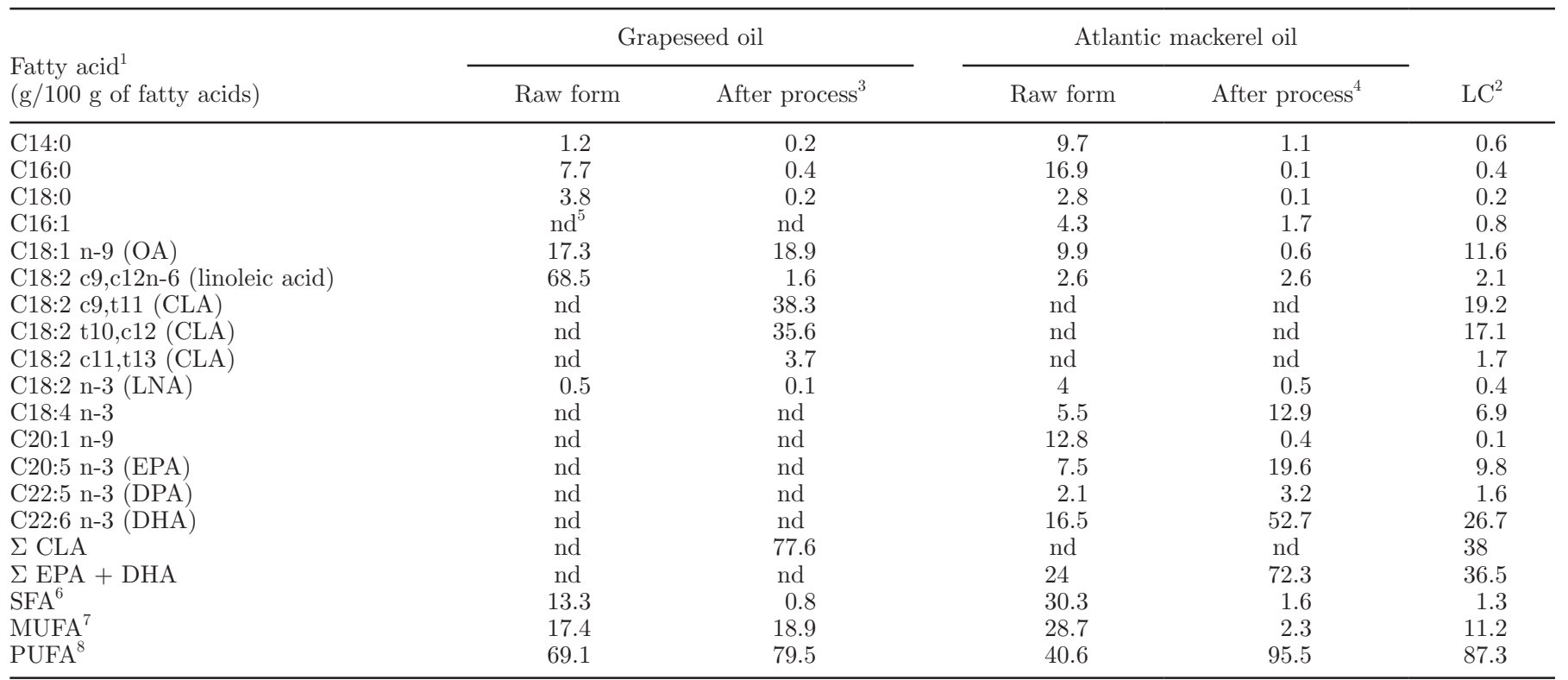

${ }^{1} \mathrm{OA}=$ oleic acid; LNA = linolenic acid; EPA = eicosapentaenoic acid; DPA = docosapentaeonic acid; DHA = docosahexaenoic acid.

${ }^{2}$ Based on grapeseed oil after the process of alkaline isomerization and crystallization of urea and Atlantic mackerel oil after the process of alkaline hydrolysis and urea complexation.

${ }^{3}$ Alkaline isomerization and crystallization of urea.

${ }^{4}$ Alkaline hydrolysis and urea complexation.

${ }^{5} \mathrm{nd}=<0.01$ or not detected.

${ }^{6} \mathrm{SFA}=\Sigma \mathrm{C} 14: 0, \mathrm{C} 15: 0, \mathrm{C} 16: 0, \mathrm{C} 17: 0, \mathrm{C} 18: 0, \mathrm{C} 20: 0, \mathrm{C} 22: 0, \mathrm{C} 23: 0$.

${ }^{7} \mathrm{MUFA}=\Sigma \mathrm{C} 14: 1, \mathrm{C} 16: 1, \mathrm{C} 17: 1, \mathrm{c} 9 \mathrm{C} 18: 1$, t9 C18:1, t11 C18:1, C20:1, C22:1, C24:1.

${ }^{8} \mathrm{PUFA}=\Sigma \mathrm{t} 6 \mathrm{C} 18: 2, \mathrm{c} 9 \mathrm{C} 18: 2, \mathrm{c} 12, \mathrm{c} 9, \mathrm{t} 11 \mathrm{C} 18: 2, \mathrm{t} 10, \mathrm{c} 12 \mathrm{C} 18: 2$, other isomers C18:2, c9,c12,c15 C18:3, C18:4, c8,c11,c14 C20:3, c11,c14,c17 C20:3, C20:4, C20:5, C22:5, C22:6. c = cis; $\mathrm{t}=$ trans.

Sweden) and trans-10,cis-12-octadecadienoate methyl (20-1826-7; Larodan Fine Chemicals AB). Heptadecanoic acid (51610 Fluka; Sigma-Aldrich Chemie GmbH) was used as an internal standard. Compositions of fatty acids in grapeseed oil before (raw form) and after the process of alkaline isomerization and urea crystallization are presented in Table 1.

The concentration of n-3 fatty acids in fish oil was increased by alkaline hydrolysis and urea complexation (Figure 2) according to a modified version of the method elaborated by Patkowska-Sokoła et al. (2009). Atlantic mackerel oil was used as a raw material (Lyse, Poland). Potassium hydroxide (p.a.), urea (p.a.), and anhydrous sodium sulfate (p.a.) were also used, as well as ethanol, methanol, and hexane as the solvents (all reagents: Avantor Performance Materials Poland Inc.).

Fatty acid methyl esters were determined using the procedures described by Christopherson and Glass (1969). Chromatographic analysis was performed with an Agilent Technologies 6890N gas chromatograph with FID detector (Agilent Technologies, Palo Alto, CA), Supelco SP-2560 capillary GC column (100 m length $\times$
$0.25 \mathrm{~mm}$ i.d., $\mathrm{d}_{\mathrm{f}}=0.20 \mu \mathrm{m}$; Supelco, Bellefonte, PA). The following oven program was used: initial temperature $140^{\circ} \mathrm{C}(2 \mathrm{~min})$, increase by $2^{\circ} \mathrm{C} / \mathrm{min}$ up to $225^{\circ} \mathrm{C}$ and isotherm for $10 \mathrm{~min}$, increase by $4^{\circ} \mathrm{C} / \mathrm{min}$ up to $240^{\circ} \mathrm{C}$ and isotherm for $10 \mathrm{~min}$. Two microliters of the sample was injected in split mode (100:1). Injector and detector temperatures were 250 and $260^{\circ} \mathrm{C}$. Helium was used as the carrier gas and nitrogen as the makeup gas. The carrier gas flow rate was $1.1 \mathrm{~mL} / \mathrm{min}$. Identification of common fatty acids was accomplished by comparison of sample peak retention times with those of FAME standard mixtures (47885-U Supelco; Sigma-Aldrich Chemie $\mathrm{GmbH})$, cis-5,8,11,14,17-eicosapentaenoic acid methyl ester (47571-U Supelco; Sigma-Aldrich Chemie $\mathrm{GmbH}$ ), and cis-4,7,10,13,16,19-docosahexaenoic acid methyl (05832 Fluka; Sigma-Aldrich Chemie GmbH). Compositions of fatty acids in Atlantic mackerel oil (raw form) and after the process of alkaline hydrolysis and urea complexation are presented in Table 1.

Lipid complex was elaborated based on grapeseed oil with synthesized CLA, and Atlantic mackerel oil enriched in n-3 fatty acids. Oil preparations were mixed 
together using a magnetic stirrer C-MAG MS 10 Ikamag (IKA-Werke GmbH \& Co. KG, Stauffen, Germany), and $\alpha$-tocopherol dissolved in methanol was then added at $200 \mathrm{mg} / 100 \mathrm{~g}$ of preparation to protect UFA against oxidation (all reagents: Avantor Performance Materials Poland Inc.).

The procedures described by Christopherson and Glass (1969) were used to determine FAME. The chromatographic analyses were made using capillary gas chromatography under the following conditions: Agilent Technologies 7890A gas chromatograph with FID detector, HP-88 capillary GC column (100 m length $\times 0.25 \mathrm{~mm}$ i.d., $\mathrm{d}_{\mathrm{f}}=0.25 \mu \mathrm{m}$; Agilent Technologies) . The following temperature program was used: initial temperature $100^{\circ} \mathrm{C}(5 \mathrm{~min})$, increase by $4^{\circ} \mathrm{C} / \mathrm{min}$ up to $140^{\circ} \mathrm{C}$, increase by $2^{\circ} \mathrm{C} / \mathrm{min}$ up to $240^{\circ} \mathrm{C}$, final isotherm for 5 min. Injection was at $1 \mu \mathrm{L}$ in split mode $(80: 1$ split ratio), injector temperature $250^{\circ} \mathrm{C}$, detector temperature $270^{\circ} \mathrm{C}$, with helium as the carrier gas. Fatty acid methyl esters standard mixtures (47885-U Supelco, Sig-
ma-Aldrich Chemie $\mathrm{GmbH}$ ) and trans-11-octadecenoic methyl ester (46905-U Supelco; Sigma-Aldrich Chemie GmbH), cis-9,trans-11-octadecadienoate methyl (201823-7; Larodan Fine Chemicals AB), trans-10, cis12-octadecadienoate methyl (20-1826-7; Larodan Fine Chemicals AB), cis-5,8,11,14,17-eicosapentaenoic acid methyl ester (47571-U Supelco; Sigma-Aldrich Chemie $\mathrm{GmbH}$ ), and cis-4,7,10,13,16,19-docosahexaenoic acid methyl (05832 Fluka; Sigma-Aldrich Chemie GmbH, Schelldorf, Germany) standards were used to identify fatty acids with Agilent ChemStation software (Agilent Technologies, Santa Clara, CA). Composition of fatty acids in LC is presented in Table 1.

Due to its oily form, the LC was nozzle sprayed onto Humokarbowit carrier to facilitate its use in dairy cow feeding. Humic-mineral preparation used in the study as the carrier is characterized by high sorptive capacity and antioxidant properties. The spraying process $(20 \%$ $\mathrm{LC} / \mathrm{kg}$ of carrier) was performed by Tronina company (PHW Tronina, Raków, Poland).
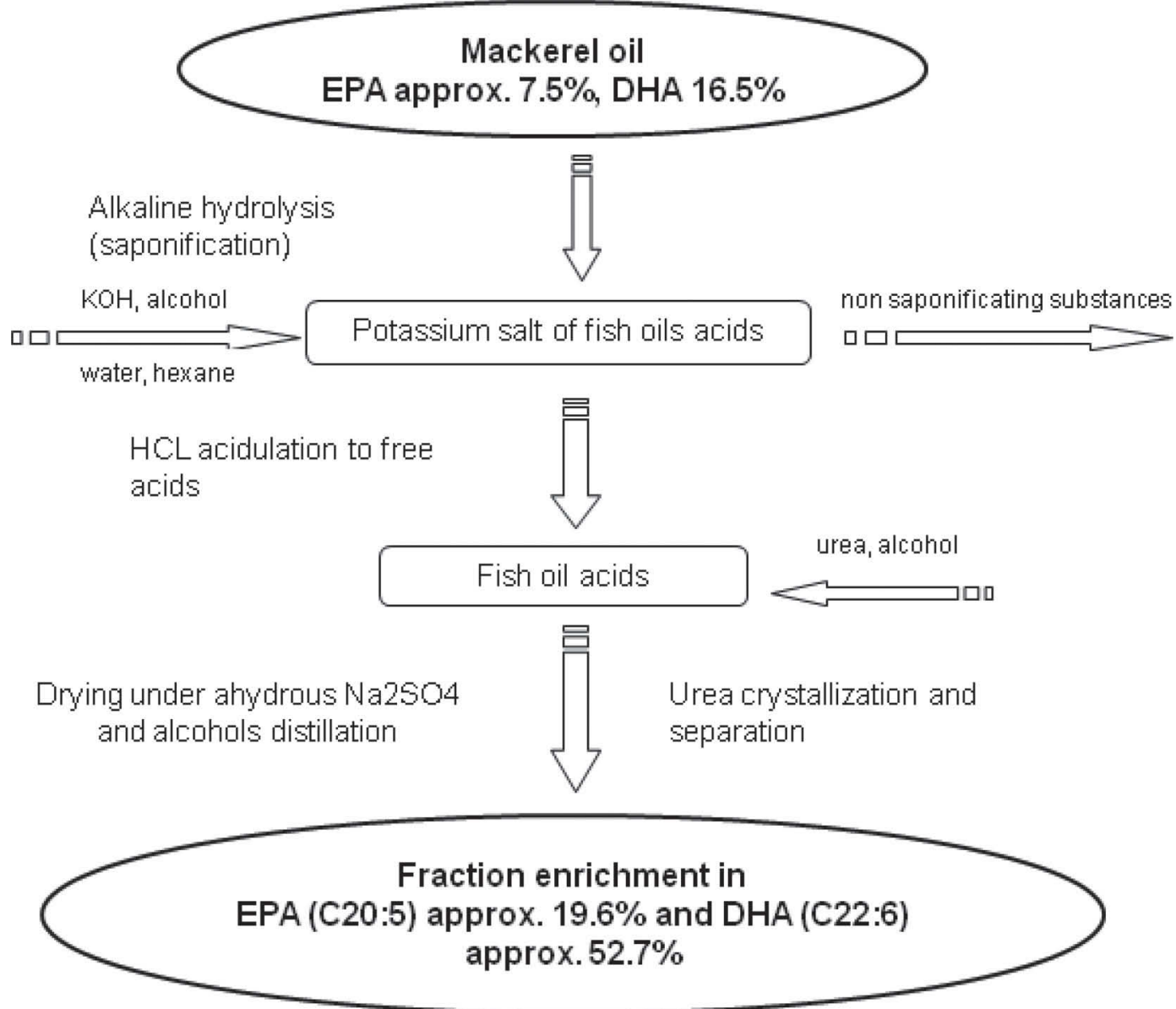

Figure 2. Scheme of Atlantic mackerel oil (fish oil) enrichment in eicosapentaenoic acid (EPA; C22:5) and docosahexaenoic acid (DHA; C22:6) acids. approx. = approximately. 


\section{Animals and Treatments}

The study was carried on 30 Polish Holstein Friesian cows of the red-white variety, approximately $600 \pm 25$ $\mathrm{kg}$ of $\mathrm{BW}$, at $70 \pm 10 \mathrm{~d}$ of lactation (multiparous cows), and average milk yield of $34.1 \pm 2.13 \mathrm{~kg}$, divided into 2 groups $(\mathrm{n}=15)$. The animals were selected from the herd of 340 cows on the basis of stage of lactation, milk yield, and live weight, and they were allocated at random to particular groups. The cows were kept in a stall system, individually blocked and fed TMR with free access to fresh water. All the cows were handled in accordance with the regulation of the Polish Council on Animal Care, and all procedures for this trial were approved by the 2nd Local Ethical Committee for Experiments on Animals in Wroclaw (No. 61/2009).

Two dietary treatments were applied: control group (CTL), and experimental group (EXP) supplemented diet with $400 \mathrm{~g} / \mathrm{d}$ of LC. The TMR were formulated according to INRA system (Strzetelski, 2009) using INRAtion 4.0 software (DJ Group, Krakow, Poland), based on chemical analyses of ingredients. Samples of TMR were pooled 3 times over experiment. The following parameters were determined: DM (method 934.01), CP (method 984.13; Kjeltec 2300 apparatus, Foss Analytical AB, Sweden), crude fat (method 920.39), crude fiber [method 978.10; Fibertec 1020 (M6) apparatus, Foss, Hillerød, Denmark], according to AOAC International (2005) procedures. The methods of Van Soest et al. (1991) were used in the analyses of NDF and ADF. The cows were allocated TMR, allowing 5\% refusals. The percentage share of ingredients and chemical composition of diets are presented in Table 2 .

\section{Experiment Design, Measurements, and Sampling Procedures}

The study was conducted for a 4-wk period. The supplements (Humokarbowit in CTL and Humokarbowit with LC in EXP) were individually administered in the morning in TMR for $30 \mathrm{~d}$.

The cows were milked twice daily (0600 and $1600 \mathrm{~h}$ ) and milk yield was recorded at each milking. Representative individual milk samples $(150 \mathrm{~mL}$ each) from the morning and evening milking were collected from cows at $\mathrm{d} 14$ and 30 for basic chemical analysis. Milk samples were immediately cooled to the temperature of $4^{\circ} \mathrm{C}$, transferred to the Laboratory of Milk Assessment and Analysis in the Institute of Animal Breeding, Wroclaw University of Environmental and Life Sciences (Poland), and analyzed within $2 \mathrm{~h}$ after collection. Basic parameters of milk (i.e., dry matter, fat, protein, and lactose) were determined by automated infrared with Infrared
150 apparatus (Bentley Instruments Inc., Chaska, MN). The hygienic status of the milk was evaluated based on SCC with Somacount 150 apparatus (Bentley Instruments Inc.). On d 14 and 30, milk samples (12 L/cow) were obtained from individual cows (pooled samples from morning and evening milking from each cow, in a ratio of $1: 1 \mathrm{vol} / \mathrm{vol}$, cooled immediately to $4^{\circ} \mathrm{C}$ ). These milk samples were used to manufacture rennet cheese as well as to determine fatty acid composition of milk and cheese, and to perform basic chemical analysis of cheese.

For chromatographic analysis, milk fat $(1 \mathrm{~g})$ was obtained after milk centrifugation at 4,000 $\times \mathrm{g}$ for $15 \mathrm{~min}$ at $4^{\circ} \mathrm{C}$ (MPW 260RH apparatus, Med. Instruments, Warsaw, Poland). Lipid extraction was performed according to the modified Folch procedure (chloroform and methanol in a volume ratio of 2:1; Christie, 1973), and methylation was performed using $2 M \mathrm{KOH}$ in methanol (Christopherson and Glass, 1969).

Rennet cheese was manufactured by the traditional method from raw fresh milk (within $24 \mathrm{~h}$ from pooled milk samples obtaining) in the cheese kettle (SKH 200 EL Advanced, Plevnik, Dobrova, Slovenia). Milk was kept cooled $\left(4^{\circ} \mathrm{C}\right)$ until processing. The milk was not

Table 2. Ingredients and chemical composition of the cow diets

\begin{tabular}{lcc}
\hline & \multicolumn{2}{c}{ Treatment $^{1}$} \\
\cline { 2 - 3 } Item & CTL & EXP \\
\hline Ingredient, \% of DM & & \\
Corn silage & 37.5 & 37.3 \\
Grass silage & 22.3 & 22.3 \\
Fresh spent grain & 7.55 & 7.53 \\
Wet beet pulp & 7.25 & 7.25 \\
Rapeseed meal & 5.82 & 5.82 \\
Soybean meal & 3.82 & 3.82 \\
Second-cut hay & 3.50 & 3.50 \\
Complete mixture & 9.22 & 9.22 \\
Humokarbowit & 2.30 & 2.30 \\
Lipid complex & - & 0.22 \\
Calcium bicarbonate & 0.27 & 0.27 \\
Vitamins and minerals & \\
Chemical composition & 0.47 & 0.47 \\
NE, MJ/kg & & \\
CP, \% & 6.92 & 7.16 \\
Crude fat, \% & 16.8 & 16.8 \\
NDF, \% & 3.44 & 3.60 \\
ADF, \% & 36.2 & 36.2 \\
Calcium, \% & 21.4 & 21.4 \\
Phosphorus, \% & 0.78 & 0.78 \\
\hline
\end{tabular}

${ }^{1}$ Treatments: CTL $=$ control group; EXP $=$ experimental group supplemented with $400 \mathrm{~g} / \mathrm{d}$ of lipid complex.

${ }^{2}$ Contained Ca, 150 g; P, 100 g; Na, 130 g; Mg, 50 g; Zn, 8,000 mg; Cu, 1,500 mg; Mn, 6,000 mg; J, 120 mg; Se, 30 mg; Co, 20 mg; vitamins: A, 12,000 IU; D, 1,600 IU; E, 5,000 mg; B, $210 \mathrm{mg}$; H, $80 \mathrm{mg}$ (Fatro Polska Ltd., Kobierzyce, Poland).

${ }^{3}$ Humic-mineral preparation (PHW Tronina, Rakow, Poland). 
pasteurized or standardized for fat content, and no starter culture was added for cheese making. Cheese were made in a pilot plant as follows: $10 \mathrm{~L}$ of cooled milk from each cow (per treatment) was heated to 32 $\pm 1^{\circ} \mathrm{C}$, for approximately $15 \mathrm{~min}$ (this temperature was kept until final heating). During milk stirring (2 min), commercial rennet (Naturen Premium 225, Chr. Hansen A/S, Hørsholm, Denmark) mixed with water for $20 \mathrm{~min}$ before application (1:30 vol/vol), was added at $0.5 \mathrm{~mL}$ per $10 \mathrm{~kg}$ of milk. Consequently, the milk was stabilized and left for coagulation. After milk had clotted (30 min), the curd was cut with the harps into $1 \mathrm{~cm}^{3}$ cubes and left for the separation of whey (20 min). Then, the curd was cut again and heated for approximately $10 \mathrm{~min}$ to $35 \pm 1^{\circ} \mathrm{C}$ to express the whey. When the whey was drained off, the curd was placed into 500 -g molds and pressed $\left(0.4 \mathrm{~kg} / \mathrm{cm}^{2}\right)$ for 8 to 12 $\mathrm{h}$ at 20 to $22^{\circ} \mathrm{C}$.

One cheese from each of 15 cows from each treatment (CTL and EXP), and period (d 14 and 30) was used for further analysis (60 cheeses total). Total DM was obtained by oven drying at $105^{\circ} \mathrm{C}$ [method PN-EN ISO 5534:2005 (Polish Committee for Standardization, 2005), SLN 115 ECO apparatus, POL-EKO-Aparatura, Wodzisław Śląski, Poland]. The pieces of cheese were lyophilized at $-55^{\circ} \mathrm{C}$ (Telstar LyoQuest 55 apparatus, Redhill, UK) and analyzed for CP (method 984.13) according to AOAC (1990), and crude fat (method 920.39) according to AOAC International (2005).

Fat from each manufactured cheese (60 pieces of cheese in total) was extracted for an examination of fatty acid composition according to the Soxhlet method (method 920.39; Büchi B-811 apparatus, Büchi Labortechnik GmbH, Essen, Germany; AOAC International, 2005). Fatty acid methylation was performed according to the transesterification method ISO 5509:2000(E) (ISO, 2000).

Identification of FAME in fat from milk and cheese was conducted using an Agilent Technologies 7890A chromatograph with FID detector, HP-88 capillary GC column $\left(100 \mathrm{~m}\right.$ length $\times 0.25 \mathrm{~mm}$ i.d., $\mathrm{d}_{\mathrm{f}}=0.25$ $\mu \mathrm{m}$; Agilent Technologies Inc.). The analysis involved a programmed run with temperature ramps under the temperature conditions described in the Production of Oil Preparations and Elaboration of LC and Feed Additive section.

\section{Statistical Analysis}

All variables were tested for normality using the Shapiro-Wilk test and when needed transformed into logarithm form to normalize their frequency distribution. Experimental data were analyzed using SAS version 9.0 (SAS Institute Inc., Cary, NC). The chemical composition and fatty acid profile of milk and cheese were analyzed using a general linear model for repeated measures ANOVA with dietary treatments $(D)$ and sampling time $(T)$ as fixed effects and their interactions $(D \times T)$ according to the model:

$$
Y_{i j k}=\mu+D_{i}+T_{j}+D \times T_{i j}+\varepsilon_{i j k},
$$

where $Y_{i j k}$ is the dependent variable, $\mu$ is the overall mean, $D_{i}$ is the effect of dietary treatment $(i=\mathrm{CTL}$ from d 14 and 30, EXP from d 14 and 30), $T_{j}$ is the effect of sampling time $(j=$ CTL and EXP from d 14; CTR and EXP from d 30), $D \times T_{i j}$ is the interaction between dietary treatments and sampling time, and $\varepsilon_{i j k}$ is the residual error.

To determine significant differences between the means for treatment groups, one-way ANOVA model was used:

$$
Y_{i j}=\mu+A_{i}+\varepsilon_{i j}
$$

where $Y_{i j}$ is the dependent variable, $\mu$ is the overall mean, $A_{i}$ is the treatment group effect ( $i=$ CTL from d 14, CTL from d 30, EXP from d 14, EXP from d 30), and $\varepsilon_{i j}$ is the residual error. Differences between treatment group means were analyzed for significance $(P<$ $0.01 ; P<0.05)$ using the Tukey test.

The data are presented as average values and accompanied by standard error of the means.

\section{RESULTS AND DISCUSSION}

\section{Lipid Complex and Feed Additive}

The process of alkaline isomerization and crystallization from urea of linoleic acid (cis-9,cis-12 C18:2) from grapeseed oil resulted in the synthesis of its conjugated dienes C18:2 in relative amounts of $38.3 \%$ (cis-9,trans-11), 35.6\% (trans-10, cis-12), and 3.7\% (cis11,trans-13) (Table 1). The preparation also included other fatty acids: MUFA and PUFA in relative amounts of 1.9 and $18.9 \%$, respectively, and SFA (C14 to C18) in the relative amount of $0.8 \%$ (Table 1 ).

In turn, the application of alkaline hydrolysis and urea complexation caused an increase in PUFA content in Atlantic mackerel oil (Table 1). In the family of n-3 fatty acids, the highest increases were noted for EPA, DHA, and stearidonic acids (C18:4; 161, 219, and 134\%, respectively). An increase in PUFA was accompanied by a decrease in SFA content from 30.3 to $1.6 \mathrm{~g} / 100 \mathrm{~g}$ of fatty acids (Table 1 ).

The composition of LC was elaborated based on oil preparations, and it contained 87.3 and $11.2 \%$ PUFA and MUFA, respectively, and $1.3 \%$ SFA. The 
Table 3. Selected parameters of milk and cheese of cows fed the 2 diets (CTL and EXP) at the 2 sampling times

\begin{tabular}{|c|c|c|c|c|c|c|c|c|}
\hline Item & \multicolumn{2}{|c|}{$\mathrm{CTL}^{1}$} & \multicolumn{2}{|c|}{$\mathrm{EXP}^{1}$} & SEM & \multicolumn{3}{|c|}{ Effect $^{2}$} \\
\hline \multicolumn{9}{|l|}{ Milk } \\
\hline DM, $\%$ & 13.4 & 13.39 & 13.09 & 12.71 & 0.126 & NS & NS & NS \\
\hline Protein, \% & 3.29 & 3.31 & 3.21 & 3.23 & 0.022 & NS & NS & NS \\
\hline Fat, $\%$ & $4.57^{\mathrm{A}}$ & $4.64^{\mathrm{A}}$ & $4.14^{\mathrm{B}}$ & $4.08^{\mathrm{B}}$ & 0.036 & $* *$ & NS & NS \\
\hline \multicolumn{9}{|l|}{ Rennet cheese } \\
\hline DM, \% & 46.76 & 47.04 & 46.79 & 46.46 & 0.117 & NS & NS & NS \\
\hline Protein, \% & 17.54 & 17.50 & 17.63 & 17.77 & 0.069 & NS & NS & NS \\
\hline Fat, $\%$ & $22.84^{\mathrm{A}, \mathrm{a}}$ & $22.76^{\mathrm{ab}}$ & $22.34^{\mathrm{bc}}$ & $22.23^{\mathrm{B}, \mathrm{c}}$ & 0.067 & $* *$ & NS & NS \\
\hline
\end{tabular}

${ }^{\mathrm{a}-\mathrm{c}}$ Means in rows marked with different lowercase superscripts differ significantly at $P \leq 0.05$.

${ }^{\mathrm{A}, \mathrm{B}}$ Means in rows marked with different uppercase superscripts differ significantly at $P \leq 0.01$.

${ }^{1} \mathrm{CTL}=$ control group; EXP = experimental group supplemented with $400 \mathrm{~g} / \mathrm{d}$ of lipid complex (LC).

${ }^{2} \mathrm{D}=\operatorname{diet} ; \mathrm{T}=$ time.

** $P<0.01$.

main components of LC were CLA isomers in relative amounts of about $38 \%$ (cis-9,trans-11, trans-10, cis-12, and cis-11,trans-13) as well as EPA and DHA in relative amounts of about $36.5 \%$ (Table 1 ).

\section{Chemical Composition of Milk and Cheese}

The elaborated feed additive (Humokarbowit with LC) supplementation to TMR did not affect the milk production level of the cows (Table 3). Lipid complex also had no effect on the dry matter, protein, and lactose content of milk, and DM and protein content of rennet cheese, except for decreases of 10.9 and $2.2 \%$ $(P<0.01)$ observed in fat level, respectively (Table 3$)$.

No effect of protected plant oil enriched in PUFA on ration dose DMI and milk yield was demonstrated by Theurer et al. (2009). In turn, the addition of fish oil alone (Shingfield et al., 2006) and in combination with marine algae (AbuGhazaleh et al., 2009) had little effect on milk yield. Numerous studies indicate, however, that dietary addition of fish oil, especially in nonprotected form, causes a decrease in milk fat content (Palmquist and Griinari, 2006; Whitlock et al., 2006; AbuGhazaleh and Holmes, 2007; Castañeda-Gutiérrez et al., 2007). In the study of Ahnadi et al. (2002), addition of protected fish oil to diets for dairy cows decreased the abundance of lipogenic enzymes mRNA (acetyl-CoA carboxylase, fatty acid synthase, stearoyl-CoA desaturase mRNA) in the mammary gland. In turn, addition of unprotected fish oil slightly decreased mRNA abundance of those enzymes but markedly reduced the amount of lipoprotein lipase mRNA. Those results demonstrated that fish oil was responsible for milk fat percentage decrease by an inhibiting gene expression of mammary lipogenic enzymes. An addition of 60 to $70 \mathrm{~g}$ of fishmeal oil in the cow's diet would be enough to inhibit milk fat synthesis (Gama et al., 2008).

Some studies have demonstrated that CLA isomers can inhibit milk fat secretion in dairy cows (Chouinard et al., 1999; de Veth et al., 2004). Milk fat synthesis is particularly inhibited by the trans-10,cis-12 isomer of CLA (Lock et al., 2006). Castañeda-Gutiérrez et al. (2005), using an addition of trans-10,cis-12 CLA in cows, observed a decrease in milk fat content, without any significant effect on milk yield and energy balance. In case of higher CLA dose, however, the energy used for milk production was lower.

\section{Milk and Cheese Fatty Acid Composition}

In our study, milk from cows treated with LC had lesser relative amounts of each fatty acid $\leq \mathrm{C} 12(P<$ 0.01 ), and greater relative amounts of fatty acids $\geq \mathrm{C} 18$, including stearic (C18:0), trans-11 C18:1, CLA isomers (cis-9,trans-11 and trans-10,cis-12), as well as EPA and DHA $(P<0.01$; Table 4$)$. Milk fat cows supplemented with LC were also characterized by lower SFA content, and higher content of MUFA and PUFA compared with the control group $(P<0.01)$. In addition, we noted the effect of sampling time on fatty acid content in milk of cows from the EXP group. Milk from d 14 of the trial had greater relative amounts of cis-9,trans-11 C18:2 $(P$ $<0.01$ ), whereas that from d 30 had greater relative amounts of trans-10,cis-12 C18:2 and DHA $(P<0.01$; Table 4).

The changes in fatty acid profile of milk fat were paralleled by changes in the fatty acid composition of cheese. The content of MUFA and PUFA increased in 
Table 4. The mean fatty acid content of total lipids of cow milk from cows fed the 2 diets (CTL and EXP) at the 2 sampling times

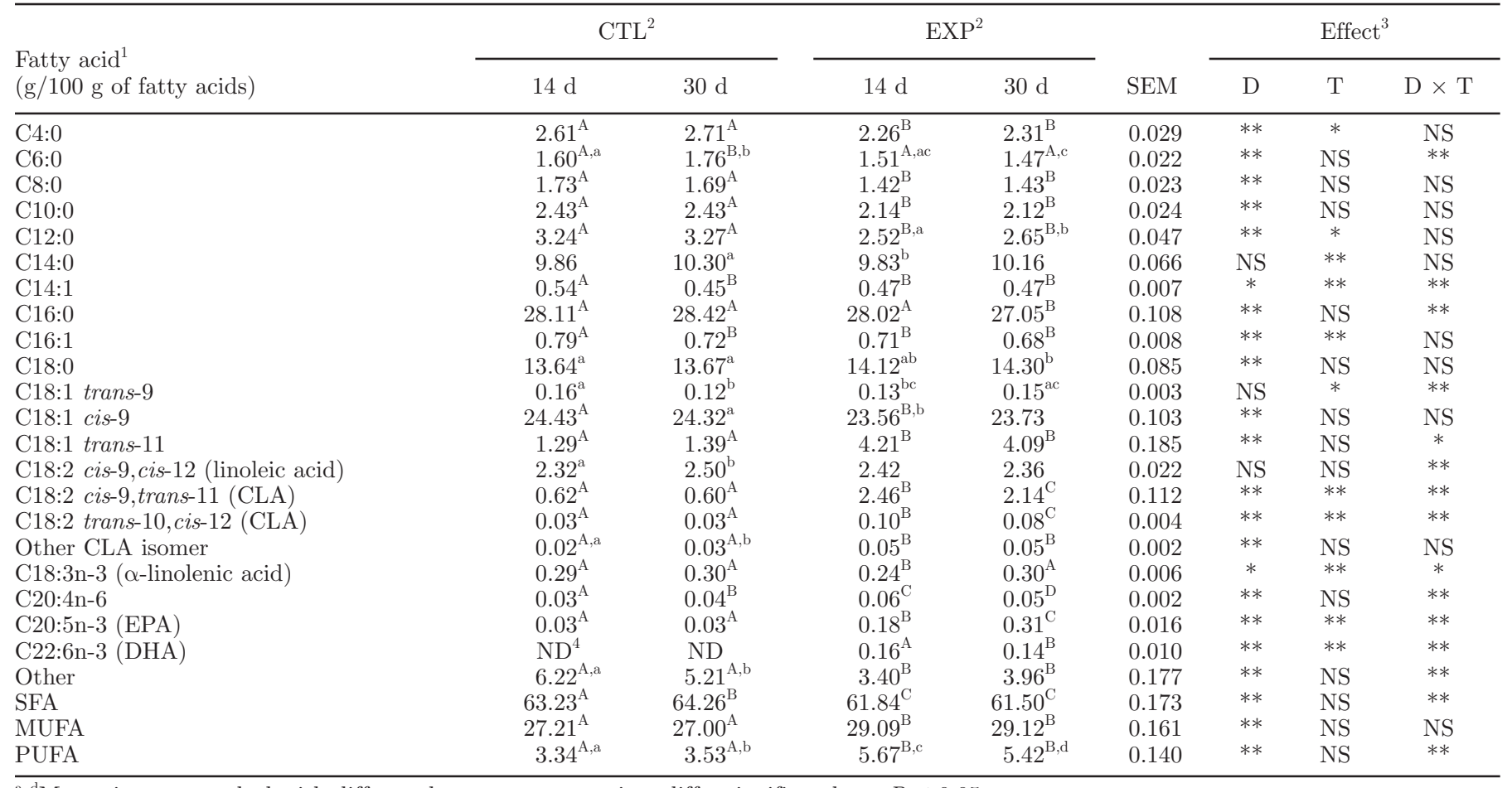

\footnotetext{
${ }^{\mathrm{a}-\mathrm{d}}$ Means in rows marked with different lowercase superscripts differ significantly at $P \leq 0.05$.

${ }^{\mathrm{A}-\mathrm{D}}$ Means in rows marked with different uppercase superscripts differ significantly at $P \leq 0.01$.

${ }^{1}$ EPA eicosapentaenoic acid; DHA = docosahexaenoic acid.

${ }^{2} \mathrm{CTL}=$ control group; EXP $=$ experimental group supplemented with $400 \mathrm{~g} / \mathrm{d}$ of lipid complex (LC).

${ }^{3} \mathrm{D}=$ diet; $\mathrm{T}=$ time.

${ }^{4} \mathrm{ND}=<0.01$ or not detected.

${ }^{*} P<0.05 ;{ }^{* *} P<0.01$
}

the EXP group, whereas SFA decreased $(P<0.01$; Table 5). The fat of cheese from the milk of cows supplemented with LC was characterized by a significantly higher content of CLA, EPA, and DHA $(P<0.01)$ (Table 4). We observed the effect of sampling time on the content of individual fatty acids also for cheese (Table 5). Concentration of both CLA isomers EPA and DHA observed in cheese fat was, however, nonsignificantly lower compared with milk fat (Table 5).

Dietary n-3 PUFA and their rumen biohydrogenation products strongly inhibit the synthesis of short- and medium-chain fatty acids in the mammary gland (Bauman et al., 2008). Whitlock et al. (2006) noted a lower concentration of short-chain SFA (C:4 to C:14) in milk from cows receiving fish oil. This was also confirmed by Osborne et al. (2008). The reduction of SFA content in milk has been previously reported when marine oils (e.g., menhaden fish oil, mackerel/herring oil, and anchovy oil) alone or in combination with vegetable oils were incorporated into dairy cow diets (Shingfield et al., 2013). Also, CLA have an effect on lipid me- tabolism and decrease the short-chain fatty acids (Bauman et al., 2008; Harvatine et al., 2009) because CLA acts on many lipogenic enzymes, such as acetyl-CoAcarboxylase and fatty acid synthase (Piperova et al., 2000), and decreases lipogenic rates and expression of genes involved in milk lipid synthesis (Baumgard et al., 2002).

Supplementation of cow feeds with LC caused a considerable increase in the content of CLA in milk fat. This is presumably related to a high content of PUFA EPA and DHA in LC, which change rumen metabolic pathways by inhibiting biohydrogenation of unsaturated fatty acids to C18:0 (Loor et al., 2005), including biohydrogenation of CLA. Some amounts of trans-11 C18:1, which is a precursor of milk fat cis-9,trans-11 CLA, are also formed during these transformations (Palmquist and Griinari, 2006). Increases in CLA content in milk fat as a result of fish oil supplementation were also reported in other studies (Donovan et al., 2000; AbuGhazaleh and Holmes, 2007; Shingfield et al., 2013). The change of CLA content after fish oil addition depends 
on the time and form of its application. In the study by Castañeda-Gutiérrez et al. (2007), ruminal infusion of fish oil caused a considerably higher CLA increase in milk fat $(6.05 \mathrm{~g} / 100 \mathrm{~g}$ of fatty acids) compared with its supplementation in the form of calcium salts (1.04 $\mathrm{g} / 100 \mathrm{~g}$ of fatty acids). These studies demonstrate the significance of PUFA microbiological biohydrogenation processes in the rumen in the process of CLA formation.

An increase in the content of CLA in milk fat observed in this study was probably also related to their high content in the LC preparation. According to Bauman et al. (2008), most of the dietary CLA isomers are subject to microbiological biohydrogenation in the rumen, first to trans-11 C18:1 (from isomer cis-9,trans-11) and trans-10 C18:1 acids (from isomer trans-10,cis-12), and then to stearic acid (C18:0), but as may be concluded from the study by Bodkowski et al. (2008), some dietary CLA isomers are transferred directly to milk fat, thereby increasing their content. In addition, vaccenic acid (trans-11 C18:1) being an intermediate product of cis-9,trans-11 C18:2 isomer biohydrogenation, is also used in mammary gland as a substrate for endogenous CLA synthesis in the presence of $\Delta^{9}$-desaturase (Corl et al., 2001). The differences in CLA content in milk fat may also result from individual differences in trans-11 C18:1 ruminal flow and from an activity of $\Delta^{9}$-desaturase in mammary gland (Castañeda-Gutiérrez et al., 2007).

Transfer of EPA and DHA to milk fat is low. Polyunsaturated fatty acids contained in fodder are intensively metabolized by ruminal microflora. An effective way of limiting of n-3 fatty acid biohydrogenation in the rumen, and thus increasing their content in milk, is fish oil supplementation in protected form (Kupczyński et al., 2012). Even more profitable results may be obtained in case of fish oil infusion directly to the abomasum (content of DHA $0.63 \mathrm{~g} / 100 \mathrm{~g}$ of fatty acids) compared with its supplementation in form of calcium salts $(0.14$ $\mathrm{g} / 100 \mathrm{~g}$ of fatty acids; Castañeda-Gutiérrez et al., 2007). Dietary addition of rumen-protected microalgae in cows feeding to a higher degree increased DHA

Table 5. The mean fatty acid content of total lipids of rennet cheese of cows fed the 2 diets (CTL and EXP) at the 2 sampling times

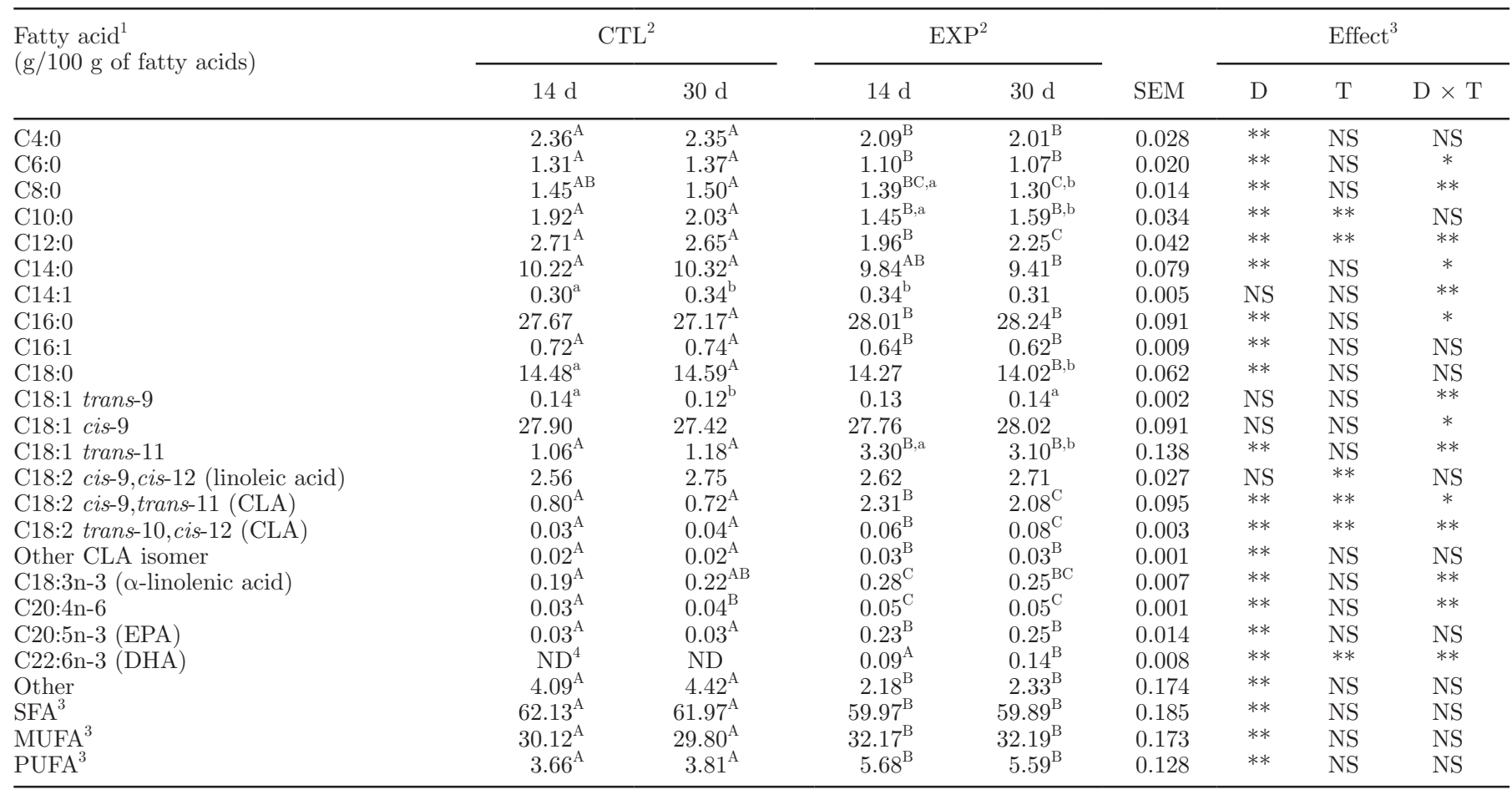

\footnotetext{
${ }_{\mathrm{a}, \mathrm{b}}$ Means in rows marked with different lowercase superscripts differ significantly at $P \leq 0.05$.

${ }^{\mathrm{A}-\mathrm{C}}$ Means in rows marked with different uppercase superscripts differ significantly at $P \leq 0.01$.

${ }^{1} \mathrm{EPA}$ eicosapentaenoic acid; DHA = docosahexaenoic acid.

${ }^{2} \mathrm{CTL}=$ control group; EXP $=$ experimental group supplemented with $400 \mathrm{~g} / \mathrm{d}$ of lipid complex (LC).

${ }^{3} \mathrm{D}=$ diet; $\mathrm{T}=$ time.

${ }^{4} \mathrm{ND}=<0.01$ or not detected.

$* P<0.05 ; * * P<0.01$.
} 
content in milk fat than protected fish oil, and 0.20 and $0.14 \mathrm{~g} / 100 \mathrm{~g}$ of fatty acids, respectively (Vahmani et al., 2013). Although the developed LC contained unprotected fatty acids, we found milk fat to have a significantly greater EPA and DHA content.

Increasing the content of dietary fatty acids (CLA and n-3 fatty acids) and maintaining a favorable ratio between n-3 and n- 6 fatty acids in milk will enhance the nutritive and therapeutic value of dairy products (Allred et al., 2006). Cheese is an important dairy product. The range of studies point that supplementation of cows' feeding dose with fish oil alone or in combination with vegetable oil or soybean products may increase the content of CLA and n-3 fatty acids in milk and cheese fat (Jones et al., 2005; Allred et al., 2006). In the study of Caroprese et al. (2013), mozzarella cheese manufactured from milk of cows fed with fish oil was characterized by higher $(P<0.05)$ content of CLA and n-3 acids. In turn, Jones et al. (2005) noted higher content of CLA, EPA, and DHA in Caerphilly cheese obtained from milk of cows fed with fish oil combined with sunflower oil, and these values were $4.48,0.10$, and $0.08 \mathrm{~g} / 100 \mathrm{~g}$ of fatty acids, respectively, compared with the control group $(0.44,0.04$, and $0.01 \mathrm{~g} / 100 \mathrm{~g}$ of fatty acids, respectively).

\section{CONCLUSIONS}

This study demonstrated that LC based on grapeseed oil with synthesized CLA and Atlantic mackerel oil enriched in n-3 PUFA could be used to change the nutritional quality and associated health value of milk and cheese from a human standpoint. Rennet cheese from milk of cows whose diet was supplemented with LC preparation was similar in fatty acid composition to that of the raw material used for its production.

\section{ACKNOWLEDGMENTS}

The authors thank the team at the Industrial Chemistry Research Institute in Warsaw, Poland, for CLA synthesis from grapeseed oil, the team at the National Marine Fisheries Research Institute in Gdynia, Poland, for fish oil enrichment in n-3 fatty acids, as well as PHU Tronina company for preparing the feed additive. The study was realized within the framework of the project "BIOFOOD - Innovative, functional products of animal origin" no. POIG.01.01.02-014-090/09, co-financed by the European Union from the Regional Development Fund within the Innovative Economy Operational Program 2007-2013. Publication was supported by Wroclaw Centre of Biotechnology, programme the Leading National Research Centre (KNOW) for 2014-2018.

\section{REFERENCES}

AbuGhazaleh, A. A., and L. D. Holmes. 2007. Diet supplementation with fish oil and sunflower oil to increase conjugated linoleic acid levels in milk fat of partially grazing dairy cows. J. Dairy Sci. 90:2897-2904.

AbuGhazaleh, A. A., R. B. Potu, and S. A. Ibrahim. 2009. The effect of substituting fish oil in dairy cow diets with docosahexaenoic acid-micro algae on milk composition and fatty acids profile. J. Dairy Sci. 92:6156-6159.

Ahnadi, C. E., N. Beswick, L. Delbecchi, J. J. Kennelly, and P. Lacasse. 2002. Addition of fish oil to diets for dairy cows. II. Effects on milk fat and gene expression of mammary lipogenic enzymes. J. Dairy Res. 69:521-531.

Allred, S. L., T. R. Dhiman, C. P. Brennand, R. C. Khanal, D. J. McMahon, and N. D. Luchini. 2006. Milk and cheese from cows fed calcium salts of palm and fish oil alone or in combination with soybean products. J. Dairy Sci. 89:234-248.

AOAC. 1990. Official Methods of Analysis. 15th ed. Association of Official Analytical Chemists, Arlington, VA.

AOAC International. 2005. Official Methods of Analysis. 18th ed. AOAC International, Gaithersburg, MD.

Bauman, D. E., J. W. Perfield II, K. J. Harvatine, and L. H. Baumgard. 2008. Regulation of fat synthesis by conjugated linoleic acid: Lactation and the ruminant model. J. Nutr. 138:403-409.

Baumgard, L. H., E. Matatashvili, B. A. Corl, D. A. Dwyer, and D. E. Bauman. 2002. Trans-10, cis-12 conjugated linoleic acid decreases lipogenic rates and expression of genes involved in milk lipid synthesis in dairy cows. J. Dairy Sci. 85:2155-2163.

Bodkowski, R., B. Patkowska-Sokoła, and W. Walisiewicz-Niedbalska. 2008. Effect of supplementing isomerised poppy seed oil with high concentration of linoleic isomer t10,c12 and c9,t11 on fat level in sheep milk and its fatty acids profile. Zuchtungskunde 80:420-427.

Caroprese, M., A. Sevi, R. Marino, A. Santillo, A. Tateo, and M. Albenzi. 2013. Composition and textural properties of Mozzarella cheese naturally-enriched in polyunsaturated fatty acids. J. Dairy Res. 80:276-282.

Castañeda-Gutiérrez, E., M. J. de Veth, A. L. Lock, D. A. Dwyer, K. D. Murphy, and D. E. Bauman. 2007. Effect of supplementation with calcium salts of fish oil on n-3 fatty acids in milk fat. J. Dairy Sci. 90:4149-4156.

Castañeda-Gutiérrez, E., T. R. Overton, W. R. Butler, and D. E. Bauman. 2005. Dietary supplements of two doses of calcium salts of conjugated linoleic acid during the transition period and early lactation. J. Dairy Sci. 88:1078-1089.

Chouinard, P. Y., L. Corneau, D. M. Barbano, L. E. Metzger, and D. E. Bauman. 1999. CLA alter milk fatty acid composition and inhibit fat secretion in dairy cows. J. Nutr. 129:1579-1584.

Christie, W. W. 1973. The isolation of lipids from tissue. Pages 39-40 in Lipid Analysis. Isolation, Separation Identification and Structural Analysis of Lipids. Pergamon Press, Oxford, UK.

Christopherson, S. W., and R. L. Glass. 1969. Preparation of milk fat methyl esters by alcoholysis in an essentially nonalcoholic solution. J. Dairy Sci. 52:1289-1290.

Corl, B. A., L. H. Baumgard, D. A. Dwyer, J. M. Griinari, B. S. Phillips, and D. E. Bauman. 2001. The role of delta(9)-desaturase in the production of cis-9, trans-11 CLA. J. Nutr. Biochem. $12: 622-630$

de Veth, M. J., E. J. M. Griinari, A. M. Pfeiffer, and D. E. Bauman. 2004. Effect of CLA on milk fat synthesis in dairy cows: Comparison of inhibition by methyl esters and free fatty acids, and relationships among studies. Lipids 39:365-372.

Dilzer, A., and Y. Park. 2012. Implication of conjugated linoleic acid (CLA) in human health. Crit. Rev. Food Sci. Nutr. 52:488-513.

Donovan, D. C., D. J. Schingoethe, R. J. Baer, J. Ryali, A. R. Hippen, and S. T. Franklin. 2000. Influence of dietary fish oil on conjugated linoleic acid and other fatty acids in milk fat from lactating dairy cows. J. Dairy Sci. 83:2620-2628.

Gama, M. A. S., P. Garnsworthy, J. M. Griinari, P. R. Leme, P. H. M. Rodrigues, L. M. O. Souza, and D. P. D. Lanna. 2008. Diet- 
induced milk fat depression: Association with changes in milk fatty acid composition and fluidity of milk fat. Livest. Sci. 115:319-331.

Harvatine, K. J., Y. R. Boisclair, and D. E. Bauman. 2009. Recent advances in the regulation of milk fat synthesis. Animal 3:40-54.

ISO. 2000. ISO 5509:2000(E). Animal and vegetable fats and oilsPreparation of methyl esters of fatty acids. 2nd ed. International Organization for Standardization, Geneva, Switzerland.

Jones, E. L., K. J. Shingfied, C. Kohen, A. K. Jones, B. Lupoli, A. S. Grandison, D. E. Beever, C. M. Williams, P. C. Calder, and P. Yaqoob. 2005. Chemical, physical, and sensory properties of dairy products enriched with conjugated linoleic acid. J. Dairy Sci. 88:2923-2937.

Kay, J. K., T. R. Mackle, M. J. Auldist, N. A. Thomsan, and D. E. Bauman. 2004. Endogenous synthesis of cis-9,trans-11 conjugated linoleic acid in dairy cows fed fresh pasture. J. Dairy Sci. $87: 369-378$.

Khanal, R. C., and K. C. Olson. 2004. Factors affecting conjugated linoleic acid (CLA) content in milk, meat, and egg: A review. Pak. J. Nutr. 3:82-98.

Kupczyński, R., M. Kuczaj, M. Szołtysik, and T. Stefaniak. 2012. Influence of fish oil, palm oil and glycerol on milk fatty acid composition and metabolism in cows during early lactation. Arch. Tierzucht 55:540-551.

Lock, A. L., B. M. Teles, J. W. Perfield II, D. E. Bauman, and L. A. Sinclair. 2006. A conjugated linoleic acid supplement containing trans-10, cis-12 reduces milk fat synthesis in lactating sheep. J. Dairy Sci. 89:1525-1532.

Loor, J. J., A. Ferlay, A. Ollier, K. Ueda, M. Doreau, and Y. Chilliard. 2005. High-concentrate diets and polyunsaturated oils alter trans and conjugated isomers in bovine rumen, blood and milk. J. Dairy Sci. 88:3986-3999.

Markiewicz-Kęszycka, M., G. Czyżak-Runowska, P. Lipińska, and J. Wójtowski. 2013. Fatty acid profile of milk-A review. Bull Vet Inst Pulawy 57:135-139.

Medeiros, S. R., D. E. Oliveira, L. J. M. Aroeira, M. A. McGuire, D. E. Bauman, and D. P. D. Lanna. 2010. Effects of dietary supplementation of rumen-protected conjugated linoleic acid to grazing cows in early lactation. J. Dairy Sci. 93:1126-1137.

Moate, P. J., W. Chalupa, R. C. Boston, and I. J. Lean. 2008. Milk fatty acids II: Prediction of the production of individual fatty acids in bovine milk. J. Dairy Sci. 91:1175-1188.

Osborne, V. R., S. Radhakrishnan, N. E. Odongo, A. R. Hill, and B. W. McBride. 2008. Effects of supplementing fish oil in the drinking water of dairy cows on production performance and milk fatty acid composition. J. Anim. Sci. 86:720-729.

Palmquist, D. L., and J. M. Griinari. 2006. Milk fatty acid composition in response to reciprocal combinations of sunflower and fish oils in the diet. Anim. Feed Sci. Technol. 131:358-369.

Patkowska-Sokoła, B., Z. Usydus, J. Szlinder-Richert, and R. Bodkowski. 2009. Technology for recovering omega-3 fatty acids from family from fish oils and protecting them against oxidative changes. Przem. Chem. 5:548-552.
Piperova, L. S., B. B. Beverly, I. Bruckental, J. Sapugna, S. E. Mills, M. P. Yurawecz, J. Fritsche, K. Ku, and R. A. Erdman. 2000. Mammary lipogenic activity, trans fatty acid and conjugated linoleic acids are altered in lactating dairy cows fed a milk fat-depressing diet. J. Nutr. 130:2568-2574.

Polish Committee for Standardization. 2005. PN-EN ISO 5534:2005. Cheese and processed cheese-Determination of the total solids content (reference method). Polish Committee for Standardization, Warsaw.

Puppel, K., B. Kuczyńska, T. Nalecz-Tarwacka, and H. Grodzki. 2013. Influence of linseed variety on fatty acid profile in cow's milk. J. Sci. Food Agric. 93:2276-2280.

Rego, O. A., P. V. Portugal, M. B. Sousa, H. J. D. Rosa, C. M. Vouzela, A. E. S. Borba, and R. J. B. Bessa. 2004. Effect of diet on the fatty acid pattern of milk from dairy cows. Anim. Res. 53:213-220.

Schroeder, G. F., J. J. Couderc, F. Bargo, and D. H. Rearte. 2005. Milk production and fatty acid profile of milk fat by dairy cows fed a winter oats (Avena sativa L.) pasture only or a total mixed ration. N. Z. J. Agric. Res. 48:187-195.

Shingfield, K. J., M. Bonnet, and N. D. Scollan. 2013. Recent developments in altering the fatty acid composition of ruminant-derived foods. Animal 7:132-162.

Shingfield, K. J., C. K. Reynolds, G. Hervas, J. M. Griinari, A. S. Grandison, and D. E. Beever. 2006. Examination of the persistency of milk fatty acid composition responses to fish oil and sunflower oil in the diet of dairy cows. J. Dairy Sci. 89:714-732

Simopoulos, A. P. 2008. The importance of the omega-6/omega-3 fatty acid ratio in cardiovascular disease and other chronic diseases. Exp. Biol. Med. (Maywood) 233:674-688.

Strzetelski, J. 2009. IZ PIB-INRA, Standards of ruminants nutrition. Nutritional value of French and domestic fodders for ruminants. IZ PIB Krakow, Poland.

Theurer, M. L., E. Block, W. K. Sanchez, and M. A. McGuire. 2009 Calcium salts of polyunsaturated fatty acids deliver more essential fatty acids to the lactating dairy cow. J. Dairy Sci. 92:2051-2056.

Vahmani, P., A. H. Fredeen, and K. E. Glover. 2013. Effect of supplementation with fish oil or microalgae on fatty acid composition of milk from cows managed in confinement or pasture systems. J. Dairy Sci. 96:6660-6670.

Van Soest, P. J., J. B. Robertson, and B. A. Lewis. 1991. Methods for dietary fiber, neutral detergent fiber, and non-starch polysaccharides in relation to animal nutrition. J. Dairy Sci. 74:3583-3597.

Walisiewicz-Niedbalska, W., B. Patkowska-Sokoła, A. W. Lipkowski, R. Bodkowski, Z. Dobrzański, H. Gwardiak, and K. Różycki. 2009. Linoleic acid with conjugated double bonds in modified vegetable oils and milk fat. Przem. Chem. 88:579-582.

Whitlock, L. A., D. L. Schingoethe, A. A. AbuGhazaleh, A. R. Hippen, and K. F. Kalscheur. 2006. Milk production and composition from cows fed small amounts of fish oil with extruded soybeans. J. Dairy Sci. 89:3972-3980. 